\title{
Conditioning to Injection Procedures and Repeated Testing Increase SCH 23390-Induced Catalepsy in Mice
}

\author{
Cibele Cristina Chinen, B.Sc., and Roberto Frussa-Filho, Ph.D.
}

The cataleptic behavior induced by the dopamine $D_{1}$ antagonist SCH 23390 (SCH) has proven to be a useful assay for investigating the sensitivity of $D_{1}$-like dopamine receptor-mediated effects during chronic drug administration. A fundamental flaw in most of these studies may be the involvement of the "repeated measures effect," a behavioral phenomenon well demonstrated for neurolepticinduced catalepsy but not yet investigated for dopamine $D_{1}$ antagonists. In this study, mice exposed for various sessions to the bar test presented a strong sensitization to the cataleptic behavior induced by repeated SCH treatment. Conversely, single tested animals exhibited a trend toward decreased catalepsy after repeated SCH treatment, which was in line with the development of a $D_{1}$-like dopamine receptor supersensitivity suggested by an increase in SKF 38393-induced grooming behavior. Surprisingly, a challenge intraperitoneal saline injection increased the cataleptic behavior of single tested mice after long-term SCH treatment. This "injection-conditioned catalepsy" was also observed after repeated treatment with the dopamine $D_{2}$ antagonists, haloperidol and metoclopramide. While these findings seem to explain some important contradictory data in the literature, they provide a new and simple animal model of the placebo effect. [Neuropsychopharmacology 21:670-678, 1999] (C) 1999 American College of Neuropsychopharmacology. Published by Elsevier Science Inc.
KEY WORDS: Catalepsy; Conditioning; SCH 23390; Dopamine $D_{1}$ receptor; Placebo effect; Reward

The ability of chronic neuroleptic treatment to produce increasing or decreasing degrees of both Parkinsonism in humans (see Hansen and Hoffman 1997) and catalepsy in laboratory animals (Barnes et al. 1990) over time remains controversial. Specifically, concerning the evolution of catalepsy during chronic haloperidol treatment, tolerance (Asper et al. 1973; Ezrin-Waters and

From the Department of Pharmacology, Escola Paulista de Medicina, Universidade Federal de São Paulo, São Paulo, SP, Brazil.

Address correspondence to: Dr. Roberto Frussa-Filho, Departamento de Farmacologia, Escola Paulista de Medicina, UNIFESP Edifício Leal Prado $1^{\circ}$ andar. Rua Botucatu, 862, CEP 04023-062, São Paulo, SP, Brazil.

Received October 12, 1998; revised April 30, 1999; accepted May 17,1999 .
Seeman 1977; Campbell and Baldessarini 1981), sensitization (Antelman et al. 1986; Kinon and Kane 1989; Barnes et al. 1990), or no effects (György et al. 1969; Moller Nielsen et al. 1974; Frussa-Filho et al. 1992) have been reported. Although the patterns of change in catalepsy responses to chronic neuroleptic treatment are influenced by multiple determinants (Barnes et al. 1990), two specific biological mechanisms seem to be of particular importance in determining the development of tolerance or sensitization: dopamine receptor supersensitivity (Ezrin-Waters and Seeman 1977; Hoffman and Beninger 1988) and a learning process due to repeated testing in the catalepsy apparatus (Iwata et al. 1989; Ferré et al. 1990), respectively. In regards to the learning process, both repeated measures in a single session after acute haloperidol administration (Stanley and Glick 1976; Hillegaart et al. 1987 and repeated observation sessions during chronic haloperidol treatment (Barnes 
et al. 1990) have been reported to markedly enhance the cataleptic behavior presented by rodents.

For many years, dopamine $\mathrm{D}_{2}$-like receptors were implicated as the only site mediating the cataleptic behavior of neuroleptics (Seeman 1980). However, in 1984, Christensen et al. (1984) first reported the cataleptogenic properties of SCH 23390, a selective antagonist of $\mathrm{D}_{1}$-like dopamine receptors (Hyttel 1983). Thus, besides providing a functional correlate of dopamine $\mathrm{D}_{1}$ receptor antagonism (Mizuki et al. 1996), SCH 23390induced catalepsy has proven to be a useful assay for investigating the functional interactions between $D_{1}$ and $D_{2}$-like dopamine receptors (see Klemm 1993). Catalepsy has also been used to investigate the sensitivity of $D_{1}$-like dopamine receptor-mediated effects during chronic drug administration. In two landmark investigations, Hess et al. $(1986,1988)$ reported that although chronic treatment of rats with SCH 23390 resulted in an increase in $\mathrm{D}_{1}$-like striatal dopamine receptors as well as in spontaneous locomotion and $\mathrm{D}_{1}$-like and $\mathrm{D}_{2}$-like dopamine agonist-induced stereotypy, no tolerance to the cataleptic effect of the drug was observed. Similarly, Lappalainen et al. (1989) reported that chronic treatment of rats with a low dose regimen $(0.1 \mathrm{mg} / \mathrm{kg})$ of SCH 23390 did not lead to the development of tolerance to the cataleptic response in the bar test. In addition, although the cataleptic effect of a higher dose regimen $(0.5 \mathrm{mg} / \mathrm{kg})$ of SCH 23390 was significantly reduced after a 6-day treatment, this subacute tolerance was gradually reversed and was no longer significant after 12 and 18 days. Different functional mechanisms were proposed to explain the lack of tolerance to SCH 23390induced catalepsy in these three studies. However, a possible involvement of a learning process due to repeated testing was not experimentally considered by Hess et al. $(1986,1988)$ or Lappalainen et al. (1989) despite the fact that the animals were repeatedly tested for catalepsy during the course of the experiments.

In order to investigate this possibility, the initial aim of the present study was to examine the effects of chronic SCH 23390 treatment on the cataleptic behavior of mice tested repeatedly over time or only once on the horizontal bar. To functionally evaluate the sensitivity of $\mathrm{D}_{1}$-like dopamine receptors after the chronic $\mathrm{SCH}$ 23390 treatment, the effects of a challenge injection of the $\mathrm{D}_{1}$-like dopamine agonist SKF 38393 on grooming behavior was also quantified. The effect of repeated measures on SCH 23390-induced catalepsy should also be of interest in light of the hypothesis that $\mathrm{D}_{1}$-like dopamine receptors are the final target from which dopamine elicits rewarding effects (see Miller et al. 1990). Indeed, according to these authors, a "repeated measures effect" on catalepsy behavior should not be expected after treatment with dopamine $\mathrm{D}_{1}$ antagonists because the reward signal upon which the conditioning depends (stimulation of dopamine $D_{1}$ receptors) is abolished. Interestingly, the present data show that mice exposed for various sessions to the bar test presented a strong sensitization to the cataleptic behavior induced by repeated treatment with SCH 23390, whereas a trend toward tolerance was observed in mice submitted to a single test but identically treated with the dopamine $\mathrm{D}_{1}$ antagonist. More important, our data clearly show that mice long-term treated with $\mathrm{SCH}$ 23390 and single tested developed "an injection-conditioned catalepsy," i.e., an increase in the cataleptic behavior induced by a saline injection. Finally, we demonstrate that this new and provocative phenomenon is also observed after long-term treatment with a selective or a preferential $\mathrm{D}_{2}$-like dopamine receptor antagonist.

\section{MATERIALS AND METHODS}

\section{General Methods}

Subjects. Male EPM-M1 mice from our own colony, weighing $30-40 \mathrm{~g}$ were used. The animals arrived at the experimental laboratory at least 10 days before the beginning of the experiments. They were housed in polypropylene cages $(32 \times 40 \times 15 \mathrm{~cm}), 15$ per cage, with access to food and water ad libitum. Light/dark cycle (lights on at 6:00 A.M., off at 6:00 P.M.) and temperature $\left(22^{\circ} \mathrm{C}\right)$ were kept constant. All experiments took place between 11:00 A.M. and 2:00 P.M. The animals were maintained and used in accordance to the guidelines of the Committee on Care and Use of Experimental Animal Resources, School of Veterinary Medicine and Animal Science of the University of São Paulo, Brazil.

Test Agents. $\mathrm{R}(+)-7$ chloro-8-hydroxy-3-methyl-1phenyl- 2,3,4,5-tetrahydro-1H-3-benzazepine ( $\mathrm{SCH} 23390$, RBI); R(+)-1-phenyl-2,3,4,5,-tetrahydro-1H-3benzazepine7,8 diol (SKF 38393, RBI), metoclopramide hydrochloride (Lepetit $\mathrm{S} / \mathrm{A}$ ), and haloperidol (Haldol injectable solution $5 \mathrm{mg} \mathrm{mL}^{-1}$, Johnson and Johnson) were used. The drugs were freshly diluted in distilled water and were given intraperitoneally (except for SKF 38393, which was given subcutaneously) in volumes not greater than $10 \mathrm{ml} / \mathrm{kg}$ body weight. Saline was used as control solution. SCH 23390, SKF 38393, and metoclopramide doses were calculated as the salt. Haloperidol was calculated as the free base.

Catalepsy Testing. Catalepsy responses were measured by means of the bar method. Mice were gently removed from their home cage by their tail and their forepaws were placed over a glass horizontal bar, $0.5 \mathrm{~cm}$ in diameter and $30 \mathrm{~cm}$ long, which was fixed at a height of $4 \mathrm{~cm}$ above the working surface. As proposed by several authors (Barnes et al. 1990; Dijk et al. 1991; Rocha et al. 1997), to perform one catalepsy determination at one time point, the animal was given three trials. The sum 
(or the average) of these trials make possible to decrease the stress-induced data variability produced by the handling procedure as compared to a single trial per determination. In each trial, the duration of catalepsy was timed from the instant the animals were firstly placed over the bar to the instant they removed both forepaws from the bar or climbed over the bar with the hind limbs. The determination of catalepsy was performed 15 and 35 min after drug administration and the animals were returned to their cages between determinations. A preset cut-off of 19 minutes was used in each determination. This long cut-off time was employed because short cut-off values have been suggested to obscure modifications in the evolution of the cataleptic behavior during chronic drug treatment regimen (Sanberg et al. 1988). As suggested by previous studies (Undie and Friedman 1988; Lipska et al. 1995), the total amount of time that the mice remained in cataleptic posture (i.e., the sum of the catalepsy durations of the six trials performed) was calculated to give the cumulative catalepsy time for each animal. The cumulative catalepsy time (in seconds) was then transformed to logarithmic values $(\ln )$ to normalize the data as proposed by Ferré et al. (1990) and this value was used to perform statistical analysis.

Grooming Testing. Grooming behavior in response to the dopamine $\mathrm{D}_{1}$ agonist SKF 38393 was selected as a measure of dopamine $D_{1}$ receptor function, since it appears to be specific for dopamine $\mathrm{D}_{1}$ receptor stimulation (Molloy and Waddington 1984; Parashos et al. 1990). Immediately after a subcutaneous injection of 10 $\mathrm{mg} / \mathrm{kg}$ SKF 38393, mice were individually observed for grooming behavior in wire mesh cages $(16 \times 30 \times 19$ $\mathrm{cm})$ free of water and food. The duration of this behavior was measured for $1 \mathrm{~min}$ at $5 \mathrm{~min}$ intervals for 60 $\mathrm{min}$. The sum of the durations (in seconds) of grooming recorded for each animal was used to perform statistical analysis.

\section{Procedures}

Experiment 1: Evolution of SCH 23390-Induced Catalepsy in Mice Submitted to Repeated Testing on the Horizontal Bar. Twenty-five mice were allocated randomly to two groups which received intraperitoneally (i.p.) $0.1 \mathrm{mg} / \mathrm{kg} \mathrm{SCH} 23390(n=13)$ or saline $(n=12)$ once a day for 15 days. On days $1,5,10$, and 15, the animals of both groups were observed for catalepsy behavior $15 \mathrm{~min}$ after the respective daily injection. Three days after the last SCH 23390 or saline injection (day 18), animals of both groups were injected subcutaneously with $10 \mathrm{mg} / \mathrm{kg}$ SKF 38393 for grooming behavior quantification. SKF 38393-induced grooming behavior was measured three days after withdrawal from SCH 23390 treatment because this time point has been reported to better display behavioral supersensitivity after withdrawal from chronic administration of dopamine receptor blockers (Frussa-Filho and PalermoNeto 1988, 1990; Vital et al. 1995).

Experiment 2: Effects of Long-Term SCH 23390 Administration on the Cataleptic Behavior of Mice Submitted to a Single Testing on the Horizontal Bar. Eighty mice were divided into five equal groups $(n=16)$ which received $0.1 \mathrm{mg} / \mathrm{kg}$, i.p. SCH $23390(\mathrm{SCH} \rightarrow)$ or saline $(\mathrm{SAL} \rightarrow)$ once a day for 14 days. On the $15^{\text {th }}$ day, animals of some groups received a challenge injection of $\mathrm{SCH} 23390(\rightarrow \mathrm{SCH})$ or saline $(\rightarrow \mathrm{SAL})$ whereas mice of one group were not injected $(\rightarrow \mathrm{NI})$. Thus, the five groups of animals were as follows: $\mathrm{SAL} \rightarrow \mathrm{SAL}$, SAL $\rightarrow \mathrm{SCH}, \mathrm{SCH} \rightarrow \mathrm{SCH}, \mathrm{SCH} \rightarrow \mathrm{SAL}$, and $\mathrm{SCH} \rightarrow \mathrm{NI}$. Fifteen minutes after their respective challenge injection, the animals were observed for the first time for catalepsy quantification. The catalepsy recording of the animals of the $\mathrm{SCH} \rightarrow \mathrm{NI}$ group was alternated with that of mice of the other four groups.

Experiment 3: Conditioned Catalepsy after Long-Term Administration of SCH 23390, Metoclopramide or Haloperidol. One hundred mice were allocated randomly to eight groups of 12-13 animals each, which received $0.1 \mathrm{mg} / \mathrm{kg}$, i.p. SCH $23390(\mathrm{SCH} \rightarrow), 30 \mathrm{mg} / \mathrm{kg}$ metoclopramide $(\mathrm{MET} \rightarrow), 1.0 \mathrm{mg} / \mathrm{kg}$ haloperidol $(\mathrm{HAL} \rightarrow$ ), or saline (SAL $\rightarrow$ ) once a day for 14 days. On the $15^{\text {th }}$ day, the animals received a challenge injection of saline $(\rightarrow \mathrm{SAL})$ or were not injected $(\rightarrow \mathrm{NI})$. Thus, the eight groups were as follows: $\mathrm{SAL} \rightarrow \mathrm{SAL}, \mathrm{SAL} \rightarrow \mathrm{NI}, \mathrm{SCH} \rightarrow$ $\mathrm{SAL}, \mathrm{SCH} \rightarrow \mathrm{NI}, \mathrm{MET} \rightarrow \mathrm{SAL}, \mathrm{MET} \rightarrow \mathrm{NI}, \mathrm{HAL} \rightarrow \mathrm{SAL}$, and HAL $\rightarrow$ NI. Fifteen minutes after the saline challenge injection, the animals were observed for the first time for catalepsy quantification. The catalepsy recording of the animals of the NI groups was alternated with that of the mice challenged with saline.

Each animal was used in only one experiment and in all the experiments the observer was blind to the identity of the animal. In the three experiments, mice were long-term treated, challenged and observed for catalepsy in different rooms.

\section{Statistics}

For experiment 1 , differences in cataleptic behavior were evaluated by $2 \times 4$ (Treatment $\times$ Sessions) analysis of variance (ANOVA) with repeated measures. For experiment 2, results were compared by one-way ANOVA and, for experiment 3, $4 \times 2$ (Pretreatment $\times$ Challenge) ANOVA was used. When ANOVA revealed significant interactions, post hoc comparisons were made by the Student Newman-Keuls test (except for group effects comparison in experiment 1, where the Student's $t$-test was used). A conventional Student's $t$-test was also used to compare grooming data of experiment 1 . 


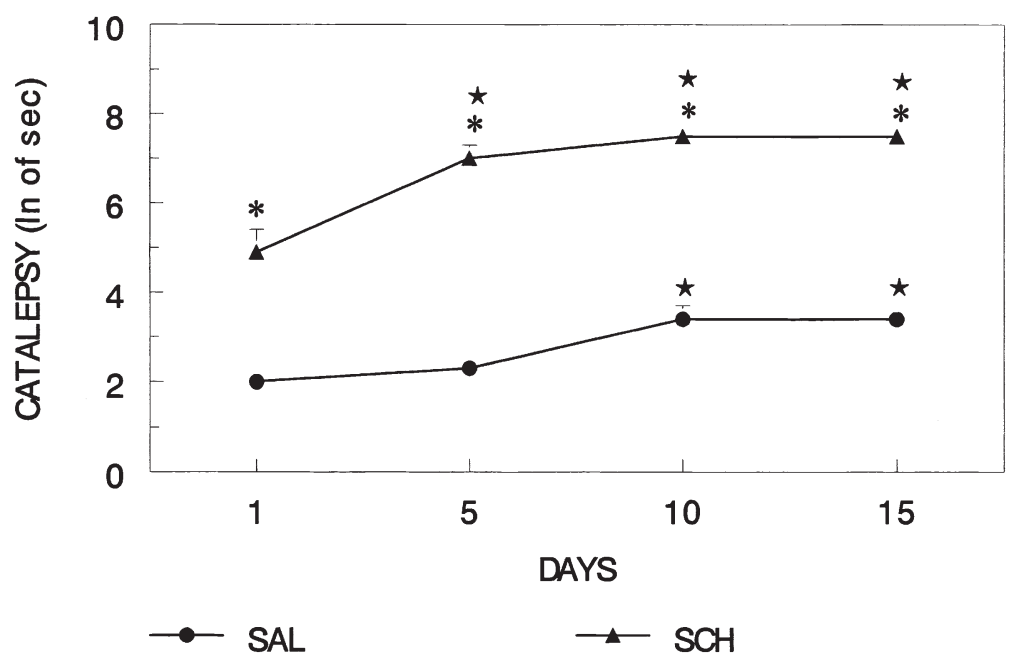

Figure 1. Evolution of SCH 23390-induced catalepsy in mice submitted to repeated testing on the horizontal bar. Animals were treated daily with injections of $0.1 \mathrm{mg} / \mathrm{kg} \mathrm{SCH} 23390$ (SCH) or saline (SAL) for 15 days and were tested for catalepsy on days 1, 5, 10, and 15 after the beginning of treatment. Data are expressed as means \pm SEM for $12-13$ animals in each group. ${ }^{*} p<.05$ compared to mice treated with saline (two-way ANOVA with repeated measures and Student's $t$-test). $\star p<.05$ compared to day 1 data for the respective treatment (two-way ANOVA with repeated measures and Student Newman-Keuls test).

\section{RESULTS}

\section{Experiment 1: Evolution of SCH 23390-Induced Catalepsy in Mice Submitted to Repeated Testing on the Horizontal Bar}

The data obtained in experiment 1 , designed to assess the influence of repeated testing on the catalepsy response of mice long-term treated with saline or $\mathrm{SCH}$ 23390, is shown in Figure 1. Two-way ANOVA with repeated measures revealed significant treatment $[\mathrm{F}(1,23)=$ 294.56; $p<.001]$, session $[\mathrm{F}(3,69)=36.30 ; p<.001]$ and treatment $\times$ session interaction $[\mathrm{F}(3,69)=6.35 ; p=$ .001] effects. Indeed, in relation to mice long-term treated with saline, post hoc analysis revealed that animals treated with SCH 23390 presented a higher catalepsy duration in all the observation sessions. In both groups, catalepsy duration significantly increased over time, but the increase in cataleptic behavior induced by repeated testing was observed earlier in mice treated with SCH 23390 when compared to mice receiving saline. Whereas the catalepsy duration presented on days 5,10 , and 15 by animals treated with SCH 23390 was significantly higher than that presented on day 1 , the catalepsy response presented only on days 10 and 15 by mice receiving saline was significantly higher than that recorded on day 1 .

Besides the increase in cataleptic behavior after repeated testing, the mice treated chronically with $\mathrm{SCH}$ 23390 also showed an increase in the grooming behavior induced by SKF 38393, three days after drug withdrawal $[\mathrm{T}(23)=2.69, p<.05]$ (Table 1$)$.

\section{Experiment 2: Effects of Long-Term SCH 23390 Administration on the Cataleptic Behavior of Mice Submitted to a Single Testing on the Horizontal Bar}

As can be seen in Figure 2, in contrast to the results of experiment 1 , no sensitization to the catalepsy response was observed when mice submitted to an identical treatment with SCH 23390 were tested for catalepsy on day 15 only. Rather, the comparison of the catalepsy duration presented by mice of the $\mathrm{SCH} \rightarrow \mathrm{SCH}$ group vs. that of the $\mathrm{SAL} \rightarrow \mathrm{SCH}$ group showed a strong trend toward decreased catalepsy. As expected, these two groups presented a catalepsy response significantly higher than that of the SAL $\rightarrow \mathrm{SAL}, \mathrm{SCH} \rightarrow \mathrm{SAL}$ and $\mathrm{SCH} \rightarrow \mathrm{NI}$ groups $[\mathrm{F}(4,75)=16.42 ; p<.001]$. Unexpectedly, however, mice of the $\mathrm{SCH} \rightarrow \mathrm{SAL}$ group showed significantly higher values of catalepsy when compared to the SAL $\rightarrow$ SAL as well as to the $\mathrm{SCH} \rightarrow \mathrm{NI}$ group, which did not differ from each other.

\section{Experiment 3: Conditioned Catalepsy after Long-Term Administration of SCH 23390, Metoclopramide or Haloperidol}

Figure 3 shows the data obtained in experiment 3, designed to replicate the "injection-induced" catalepsy observed after long-term SCH 23390 treatment in experiment 2 and to verify if such a phenomenon would also be observed after repeated administration of the selective and preferential dopamine $\mathrm{D}_{2}$ antagonists metoclo-

Table 1. Effect of withdrawal from long-term treatment with SCH 23390 on SKF 38393-induced grooming behavior in mice

\begin{tabular}{lcc}
\hline Long-term treatment & Challenge & Grooming duration (sec) \\
\hline Saline & SKF 38393 & $215.2 \pm 4.1$ \\
SCH 23390 & SKF 38393 & $234.7 \pm 5.8^{a}$ \\
\hline
\end{tabular}

Mice were long-term treated with SCH 23390 or saline as described in Figure 1. Seventy-two hours after withdrawal from their respective treatments, all the animals received $10 \mathrm{mg} / \mathrm{kg}$ SKF 38393 s.c. and grooming behavior was quantified. Data are expressed as the mean \pm SEM for 1213 animals in each group.

${ }^{a} p<.05$ compared to mice treated with saline (Student's $t$-test). 


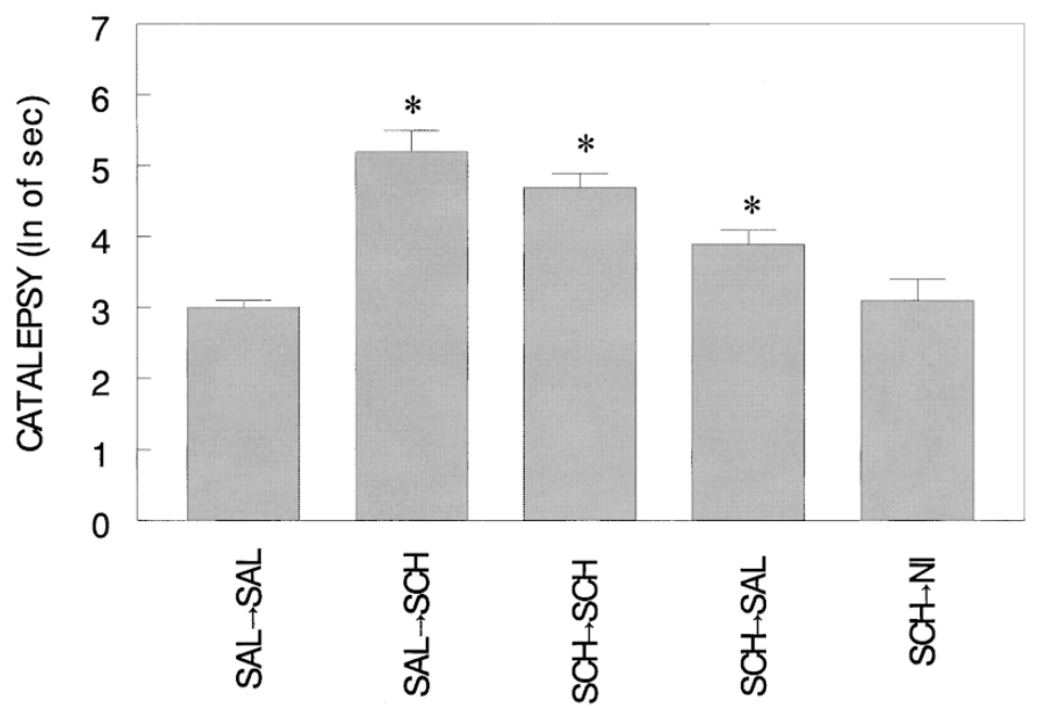

Figure 2. Effects of long-term SCH 23390 administration on the cataleptic behavior of mice submitted to a single test on the horizontal bar. Animals were treated daily with i.p. injections of $0.1 \mathrm{mg} / \mathrm{kg} \mathrm{SCH} 23390(\mathrm{SCH} \rightarrow)$ or saline $(\mathrm{SAL} \rightarrow$ ) for 14 days and tested on day 15 after challenge i.p. injection of SCH 23390 $(\rightarrow \mathrm{SCH})$ or saline $(\rightarrow \mathrm{SAL})$. A group of $\mathrm{SCH}$ 23390-pretreated animals were not injected $(\rightarrow \mathrm{NI})$ on the test day. Data are expressed as the mean \pm SEM for 16 animals in each group. ${ }^{*} p<.05$ compared to mice of the SAL $\rightarrow$ SAL and $\mathrm{SCH} \rightarrow \mathrm{NI}$ groups (one-way ANOVA and Student Newman-Keuls test). pramide and haloperidol, respectively. Two-way ANOVA revealed significant pretreatment $[\mathrm{F}(3.92)=$ $26.80 ; p<.001]$ and challenge $[\mathrm{F}(1,92)=13.99 ; p=.002]$ effects. The pretreatment $\times$ challenge interaction effect was not significant $[\mathrm{F}(3,92)=1.206 ; p=.312]$. In agreement with the data of experiment 2, post hoc analysis revealed that mice of the $\mathrm{SCH} \rightarrow \mathrm{SAL}$ group spent significantly more time in catalepsy than animals of the $\mathrm{SCH}$ $\rightarrow \mathrm{NI}$ and SAL $\rightarrow$ SAL groups, which did not differ from each other. This "injection-conditioned" catalepsy was also observed after long-term haloperidol treatment. Indeed, although the duration of catalepsy presented by mice of the HAL $\rightarrow$ NI group was significantly higher than that of the SAL $\rightarrow$ SAL group, it was significantly lower than that of the HAL $\rightarrow$ SAL group. Although no significant difference in catalepsy duration was observed between the MET $\rightarrow$ SAL and MET $\rightarrow$ NI groups, an "injection-conditioned" catalepsy after metoclopra- mide treatment was suggested by the fact that, unlike the MET $\rightarrow$ NI group, the catalepsy duration presented by mice of the MET $\rightarrow$ SAL group was significantly higher than those of the SAL $\rightarrow$ SAL or SAL $\rightarrow$ NI groups. Finally, it is important to note that no difference in catalepsy duration was observed between the SAL $\rightarrow \mathrm{SAL}$ and SAL $\rightarrow$ NI groups.

\section{DISCUSSION}

The major findings of the present investigation were that: 1) mice treated daily with SCH 23390 for 15 days and submitted to repeated testing on the horizontal bar presented a strong increase (sensitization) in cataleptic behavior over time; 2) although it developed more slowly and was much smaller in magnitude, sensitization was also observed in the multiple test long-term sa-

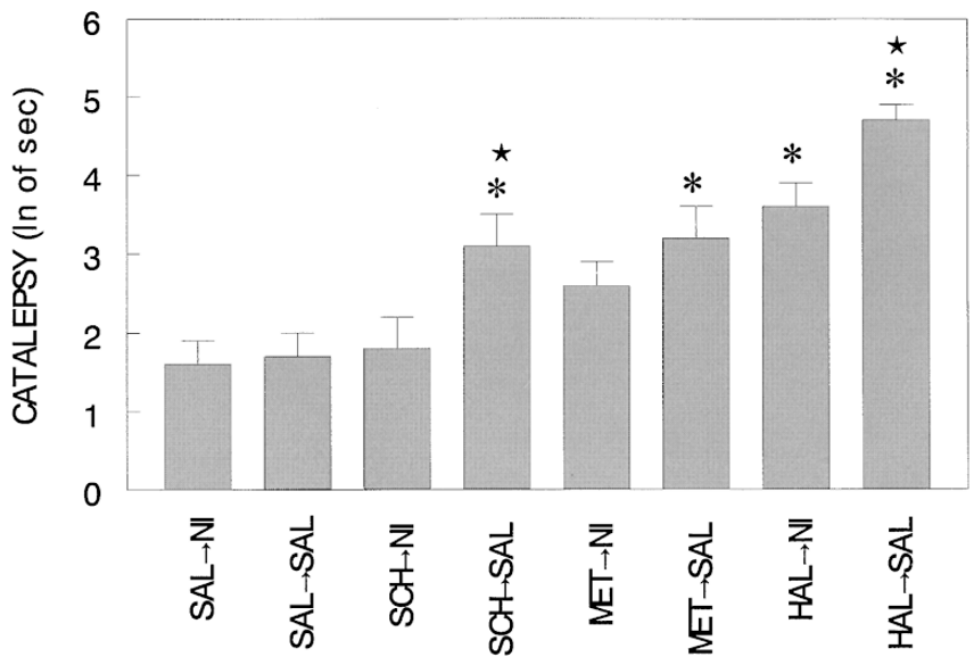

Figure 3. Injection-conditioned catalepsy after long-term administration of SCH 23390, metoclopramide or haloperidol. Animals were treated daily with i.p. injections of $0.1 \mathrm{mg} / \mathrm{kg} \mathrm{SCH} 23390$ $(\mathrm{SCH} \rightarrow), 30 \mathrm{mg} / \mathrm{kg}$ metoclopramide $(\mathrm{MET} \rightarrow), 1.0$ $\mathrm{mg} / \mathrm{kg}$ haloperidol $(\mathrm{HAL} \rightarrow)$, or saline $(\mathrm{SAL} \rightarrow$ ) for 14 days and tested on day 15 after a challenge injection of saline $(\rightarrow \mathrm{SAL})$ or after receiving no injection $(\rightarrow \mathrm{NI})$. Data are expressed as the mean \pm SEM for $12-13$ animals in each group. ${ }^{*} p<.05$ compared to mice of the SAL $\rightarrow$ SAL and SAL $\rightarrow$ NI groups. $\star p<.05$ compared to the respective "non-injected" group (submitted to the same pretreatment). Two-way ANOVA and Student Newman-Keuls test. 
line-treated group; 3 ) the sensitization to the cataleptic behavior in the multiple test $\mathrm{SCH} 23390$-treated group was observed in spite of the development of a $\mathrm{D}_{1}$-like dopamine receptor supersensitivity which was suggested by an increase in SKF 38393-induced grooming behavior; 4) mice treated daily with SCH 23390 for 15 days and submitted to a single test showed a trend toward decreased catalepsy; 5) these animals also developed an injection-conditioned cataleptic behavior which was also verified after both metoclopramide and haloperidol long-term treatments.

The marked effect of repeated testing described in experiment 1 seems to clarify some controversial data in the literature. For example, as mentioned before, Hess et al. $(1986,1988)$ did not observe tolerance to the cataleptic behavior of rats treated with SCH 23390 for 21 days in spite of verifying an increase in $\mathrm{D}_{1}$-like striatal dopamine receptors as well as in spontaneous locomotion and in the stereotyped behavior induced by $\mathrm{D}_{1}$-like or $\mathrm{D}_{2}$-like dopamine receptor agonists. Since in both studies (Hess et al. 1986, 1988) the rats were repeatedly tested for catalepsy during the course of the experiments, the absence of the expected tolerance might have been due to repeated testing. On the other hand, in contrast to the present data, Hess et al. (1986, 1988) did not observe sensitization to the cataleptic behavior of rats repeatedly treated with SCH 23390. Indeed, the sensitization phenomenon might be expected in this context since in some experiments rats were tested 6 times for catalepsy during the course of the chronic SCH 23390 treatment. However, a likely explanation for the absence of sensitization in these experiments is a ceiling effect due to the short cut-off time (120 sec) employed by Hess et al. $(1986,1988)$.

The increase in SCH 23390-induced catalepsy produced by repeated testing, verified herein, might also explain why the initial tolerance to the cataleptic behavior induced by SCH 23390 was gradually reversed and no longer significant in the experiment performed by Lappalainen et al. (1989).

As with mice receiving chronic administration of SCH 23390, mice treated chronically with saline and tested repeatedly on the horizontal bar demonstrated significantly higher catalepsy over time. The fact that drug-free or placebo-treated mice and rats, when placed repeatedly on a bar with an imposed posture, "learn" to maintain, even during long periods of time, such posture has been previously reported in some studies (Sanberg et al. 1988; Brown and Handley 1980; Amir et al. 1981; Ferré et al. 1990). According to Ferré et al. (1990), the most probable cause of this repeated testing effect is the animal's avoidance of manipulation when both forepaws touch the floor, being well-known that handling is a stressor (Axelrod and Reisine 1984). Consequently, the animal would be forced into an abnormal posture and then trained to maintain that pos- ture. In the present study, the increase in cataleptic behavior induced by repeated testing was observed later in mice treated with saline when compared to mice receiving SCH 23390. Interestingly, some studies have reported a repeated testing effect for the catalepsy bar test in haloperidol-treated mice or rats but not in animals receiving saline (Stanley and Glick 1976; Iwata et al. 1989; Barnes et al. 1990). Thus, one might be led to suspect that a pharmacological component of cataleptic behavior would be able to potentiate a learning component of this behavior. In contrast, Ferré et al. (1990) reported that 48 hours after haloperidol or saline administration and testing, a second test on the horizontal bar without any treatment revealed a significantly longer duration of catalepsy in the previously salinetreated animals than in the previously haloperidoltreated ones. Concerning our results, we considered the possibility that in addition to a repeated testing effect an injection conditioning phenomenon might have potentiated the catalepsy behavior of mice treated chronically with SCH 23390. To test this hypothesis, a saline-challenged group and a non-challenged group were included in experiment 2 , in which the effects of long-term treatment with SCH 23390 were evaluated in mice single tested for catalepsy.

In contrast to mice treated chronically with $\mathrm{SCH}$ 23390 and tested repeatedly for catalepsy, mice submitted to an identical treatment with the dopamine $\mathrm{D}_{1}$ receptor antagonist, but tested for catalepsy on day 15 only, presented a strong trend toward decreased catalepsy. This effect was probably related to the development of a $D_{1}$-like dopamine receptor supersensitivity after long-term SCH 23390, which has been demonstrated in binding studies (Creese and Chen 1985; Hess et al. 1986, 1988) and was behaviorally suggested earlier (Parashos et al. 1990) and in the present study by an increase in SKF 38393-induced grooming.

The longer catalepsy duration presented by mice treated chronically with SCH 23390 and challenged with saline (group SCH $\rightarrow$ SAL) compared to mice submitted to an identical long-term treatment with $\mathrm{SCH}$ 23390 but not challenged with any injection (group $\mathrm{SCH} \rightarrow \mathrm{NI}$ ) as well as compared to mice chronically treated and challenged with saline (group SAL $\rightarrow$ SAL), strongly suggests the development of a drug injectionconditioning phenomenon, which is, perhaps, the most striking finding of the present study. Thus, the interoceptive cues and/or the akinesia induced by SCH 23390 would be themselves sufficiently distinct stimuli to be conditioned to the injection procedure, thereby calling forth an enhanced response following a subsequent saline injection. In other words, the phenomenon would be a classical conditioned response in which SCH 23390 (unconditioned stimulus, UCS) was associated with previously neutral stimulus, i.e., the injection procedure (conditioned stimulus, CS) for 14 times, producing 
akinesia (unconditioned response). On day 15, saline was substituted for SCH 23390 and the conditioned stimulus (injection procedure) alone would induce akinesia (conditioned response), thereby increasing the duration of the cataleptic behavior. This conditioned response could explain why, in experiment 1 , the increase in the cataleptic behavior induced by repeated testing was observed earlier in mice treated with SCH 23390 than in mice receiving saline. It could also explain why, in experiment 2, only a trend toward decreased catalepsy (but not a significant effect) was observed after long-term SCH 23390 administration in mice single tested for catalepsy (group $\mathrm{SCH} \rightarrow \mathrm{SCH}$ vs group $\mathrm{SAL} \rightarrow \mathrm{SCH}$ ).

The aims of experiment 3 were twofold: first to replicate the conditioned cataleptic response observed after long-term treatment with SCH 23390; second, to verify if such a conditioned response would also be induced after repeated administration of the selective or the preferential $\mathrm{D}_{2}$-like dopamine antagonists metoclopramide and haloperidol, respectively. In this respect, whereas a challenge injection of saline did not modify the catalepsy duration presented by mice chronically treated with saline, it increased significantly the cataleptic behavior of mice treated chronically with the three dopamine receptor antagonists. Interestingly, the duration of catalepsy behavior exhibited by mice treated with haloperidol and not challenged with saline (group HAL $\rightarrow \mathrm{NI}$ ) was significantly longer than the cataleptic behavior presented by mice treated chronically with saline (groups SAL $\rightarrow$ SAL and SAL $\rightarrow \mathrm{NI}$ ), which was probably due to residual levels of the neuroleptic. If this is the case, the present data suggest that the conditioned catalepsy can potentiate the unconditioned one, further supporting the possibility that the repeated testing effect was higher in the SCH 23390-treated mice than in the saline-treated animals (experiment 1) because of an additional effect of the drug injection-conditioned phenomenon.

The fact that, like SCH 23390, repeated treatment with classical neuroleptics can induce an injection procedure-conditioned cataleptic behavior may have both experimental and clinical implications. For example, this conditioning phenomenon could be related to the development of sensitization to the cataleptic behavior of animals treated chronically with neuroleptics but not submitted to repeated testing (Antelman et al. 1986; Barnes et al. 1990). Thus, although tolerance is typically observed with this type of paradigm, a robust injection procedure-conditioning phenomenon could be related to these unexpected results. Conditioned catalepsy could also explain why in a recent study, Ushijima et al. (1995) verified sensitization to the cataleptic behavior induced by challenge injections of SCH 23390 or haloperidol, but only in mice tested many days after withdrawal from chronic treatments (when the opposite ef- fects of a dopamine receptor up regulation on catalepsy had probably vanished).

From a clinical point of view, since catalepsy is a well accepted model of neuroleptic-induced Parkinsonism, it is tempting to speculate if this drug administration-conditioning phenomenon has anything to do with the controversy concerning the development of tolerance to neuroleptic-induced Parkinsonism in humans (see Hansen and Hoffman 1997). Interestingly, it has already been suggested that psychological factors related to the placebo effect may play a fundamental role in the treatment of neuroleptic-induced Parkinsonism (St. Jean et al. 1964a,b). However, it should be noted that one must always be wary of extrapolating clinical relevance from animal data.

The above concern notwithstanding, the neurolepticinduced conditioned catalepsy may provide a new and simple animal model of the placebo (or, in such a case, nocebo) effect. This should be of interest because although the view of placebo as a conditioned response is not new, previous analyses have remained at a descriptive rather than an experimental level (see Suchman and Ader 1992). As pointed out by Schiff (1982), since the original observation of Pavlov (1927) that some symptoms seen with an acute morphine injection could be elicited by preinjection procedure alone, numerous investigators demonstrated the classical conditioning of morphine responses (see Lynch et al. 1976). In this respect, hyperactivity and stereotyped behaviors induced by dopamine agonists such as apomorphine, amphetamine and L-DOPA have also been conditioned in rodents (Pickens and Crowder 1967; Tilson and Rech 1973; Schiff et al. 1980; Schiff 1982; Hiroi and White 1989; Carey 1992). However, in all of these studies the conditioned stimulus was an injection procedure with signals such as tone and/or specific environments. In our experiments, mice were long-term treated, challenged and observed for catalepsy in different rooms. In addition, no kind of signals were associated with the injection procedures. Thus, as far as we know, this is the first study to show a classical conditioning of a response induced by dopamine antagonists and a classical conditioning of a dopaminergic agent response in which the conditioned stimulus was injection procedure only. In this respect, it should be acknowledged that the catalepsy tests are presumably a sample observation of a state produced by SCH 23390 (or neuroleptics). Thus, the injection-procedure conditioning to the drug effects observed after repeated treatment should also appear in home-cage controls or should also be detected in other behavioral models that are able to measure motor activity. This is an interesting working hypothesis.

Dopamine systems of the brain have extensively been implicated in mediating reward-related behavior (Wise and Bozarth 1987; Wise and Rompre 1989; Di Chiara 1995; Ikemoto et al. 1997). Within this context, 
the findings described in the present investigation seem to be of special relevance as regards the hypothesis that $\mathrm{D}_{1}$-like dopamine receptors are the final target from which dopamine elicits rewarding effects (see Miller et al. 1990). According to this hypothesis, the motor signals in the striatum which generate the cataleptic behavior induced by dopamine $\mathrm{D}_{1}$ antagonists would not become linked by the reward signal to the sensory conditions in which they habitually occur (the apparatus in which the drug is given, or the circumstances associated with drug injection). As a consequence, the "repeated measures effect" on catalepsy behavior should not be expected in animals treated with dopamine $D_{1}$ antagonists (Miller et al. 1990). In marked opposition to this premise, we demonstrated that mice treated chronically with SCH 23390 not only showed a strong repeated measures effect in the catalepsy bar test, but also presented a conditioned cataleptic response to the injection procedure alone. Although the conjecture that dopamine $\mathrm{D}_{1}$ receptors are the "final common pathway" for reward is supported by several other behavioral measures to which dopamine is related (see Miller et al. 1990), the present findings may provide new impetus for further characterization of the role of $\mathrm{D}_{1}$-like dopamine receptors in the reward function.

\section{ACKNOWLEDGMENTS}

This research was supported by a fellowship from Fundação de Amparo a Pesquisa do Estado de São Paulo (FAPESPProc. 97/12915-9 and Proc. 99/00526-3) and from Conselho Nacional de Desenvolvimento Científico e Tecnológico (CNPqProc. 522975/95-0).

\section{REFERENCES}

Amir S, Brown ZW, Amit Z, Ornstein K (1981): Body pinch induces long lasting cataleptic like immobility in mice: Behavioral characterization and the effect of naloxone. Life Sci 28(10):1189-1194

Antelman SM, Kocan D, Edwards DJ, Knopf S, Perel JM, Stiller R (1986): Behavioral effects of a single neuroleptic treatment grow with the passage of time. Brain Res 385(1):58-67

Asper H, Baggiolini M, Burki HR, Lauener H, Ruch W, Stille G (1973): Tolerance phenomena with neuroleptics catalepsy, apomorphine stereotypies and striatal dopamine metabolism in the rat after single and repeated administration of loxapine and haloperidol. Eur J Pharmacol 22(5):287-294

Axelrod J, Reisine TD (1984): Stress hormones: Their interaction and regulation. Science 224(4648):452-459

Barnes DE, Robinson B, Csernansky JG, Bellows EP (1990): Sensitization versus tolerance to haloperidol-induced catalepsy: Multiple determinants. Pharmacol Biochem Behav 36(4):883-887
Brown J, Handley SL (1980): The development of catalepsy in drug-free mice on repeated testing. Neuropharmacology 19(7):675-678

Campbell A, Baldessarini RJ (1981): Tolerance to behavioral effects of haloperidol. Life Sci 29(13):1341-1346

Carey RJ (1992): Pavlovian conditioning of L-dopa induced movement. Psychopharmacology 107(2-3):203-210

Christensen AV, Arnt J, Hyttel J, Larsen JJ, Svendsen O (1984): Pharmacological effects of a specific dopamine $\mathrm{D}_{1}$ antagonist SCH 23390 in comparison with neuroleptics. Life Sci 34(16):1529-1540

Creese I, Chen A (1985): Selective $D_{1}$ dopamine receptor increase following chronic treatment with SCH 23390. Eur J Pharmacol 109(1):127-128

Di Chiara G (1995): The role of dopamine in drug abuse viewed from the perspective of its role in motivation. Drug Alcohol Depend 38(2):95-137

Dijk S, Krugers HJ, Korf J (1991): The effect of teophylline and immobilization stress on haloperidol-induced catalepsy and on metabolism in the striatum and hippocampus, studied with lactograph. Neuropharmacology 30(5):469-473

Ezrin-Waters C, Seeman P (1977): Tolerance of haloperidol catalepsy. Eur J Pharmacol 41(3):321-327

Ferré S, Guix T, Prat G, Jane F, Casas M (1990): Is experimental catalepsy properly measured? Pharmacol Biochem Behav 35(4):753-757

Frussa-Filho R, Otoboni JR, Uema FT, Palermo-Neto J (1992): Effects of age and isolation on the evolution of catalepsy during chronic haloperidol treatment. Braz J Med.Biol Res 25(9):925-928

Frussa-Filho R, Palermo-Neto J (1988): Effects of single and long-term metoclopramide administration on openfield and stereotyped behaviour of rats. Eur J Pharmacol 149(3):323-329

Frussa-Filho R, Palermo-Neto J (1990): Effects of single and long-term administration of sulpiride on open-field and stereotyped behaviour of rats. Braz J Med Biol Res 23(5):463-472

György L, Pfeifer KA, Hajtman B (1969): Modification of certain central nervous effects of haloperidol during longterm treatment in the mouse and rat. Psychopharmacologia (Berl) 16(3):223-233

Hansen TE, Hoffman WF (1997): Drug-induced Parkinsonism. In: Yassa R, Nair NPV, Jeste DV (eds). NeurolepticInduced Movement Disorders. New York: Cambridge University Press, pp 341-380

Hess EJ, Albers LJ, Le H, Creese I (1986): Effects of chronic SCH 23390 treatment on the biochemical and behavioral properties of $D_{1}$ and $D_{2}$ dopamine receptors: potentiated behavioral responses to a $D_{2}$ dopamine agonist after selective $\mathrm{D}_{1}$ dopamine receptor up-regulation. J Pharmacol Exp Ther 238(3):846-854

Hess EJ, Norman AB, Creese I (1988): Chronic treatment with dopamine receptor antagonists: behavioral and pharmacologic effects on $D_{1}$ and $D_{2}$ dopamine receptors. J Neurosci 8(7):2361-2370

Hillegaart V, Ahlenius S, Magnusson O, Fowler C J (1987): Repeated testing of rats markedly enhances the duration of effects induced by haloperidol on treadmill loco- 
motion, catalepsy and a conditioned avoidance response. Pharmacol Biochem Behav 27:159-164

Hiroi N, White NM (1989): Conditioned stereotypy: behavioral specification of the UCS and pharmacological investigation of the neural change. Pharmacol Biochem Behav 32(1):249-258

Hoffman DC, Beninger RJ (1988): Conditional tolerance to haloperidol-induced catalepsy: Striatal dopamine receptor supersensitivity is a possible explanation. Psychopharmacology (Berl) 95(1):142-145

Hyttel J (1983): SCH 23390—the first selective dopamine $D_{1}$ antagonist. Eur J Pharmacol 91(1):153-154

Ikemoto S, Glazier BS, Murphy JM, McBride WJ (1997): Role of dopamine $D_{1}$ and $D_{2}$ receptors in the nucleus accumbens in mediating reward. J Neurosci 17(21):8580-8587

Iwata S, Izumi K, Shimizu T, Fukuda T (1989): Effects of repeated testing on the incidence of haloperidolinduced catalepsy in mice. Pharmacol Biochem Behav 33(3):705-707

Lipska BK, Jaskiw GE, Braun AR, Weinberger DR (1995): Prefrontal cortical and hippocampal modulation of haloperidol-induced catalepsy and apomorphineinduced stereotypic behaviors in the rat. Biol Psychiatry 38: 255-262

Kinon BJ, Kane JM (1989): Difference in catalepsy response in inbred rats during chronic haloperidol treatment is not predictive of the intensity of behavioral hypersensitivity which subsequently develops. Psychopharmacology (Berl) 98(4):465-471

Klemm WR (1993): The catalepsy of blocked dopaminergic receptors. Psychopharmacology (Berl) 111(2):251-253

Lappalainen J, Hietala J, Syvälahti E (1989): Differential tolerance to cataleptic effects of SCH 23390 and haloperidol after repeated administration. Psychopharmacology (Berl) 98(4):472-475

Lynch JJ, Stein EA, Fertziger AP (1976): An analysis of 70 years of morphine classical conditioning: Implications for clinical treatment of narcotic addiction. J Nerv Mental Disease 163(1):47-58

Miller R, Wickens JR, Beninger RJ (1990): Dopamine $D_{1}$ and $D_{2}$ receptors in relation to reward and performance: $A$ case for the $D_{1}$ receptor as a primary site of therapeutic action of neuroleptic drugs. Progr Neurobiol 34(2):143183

Mizuki Y, Ushijima I, Yamada M (1996): Effects of chronic methamphetamine on SCH 23390- or haloperidolinduced catalepsy, and effects of coadministration of SCH 23390 or haloperidol in mice. Pharmacol Biochem Behav 53(2):437-440

Moller Nielsen I, Fjalland B, Pedersen V, Nymark M (1974): Pharmacology of neuroleptics upon repeated administration. Psychopharmacologia (Berl) 34(2):95-104

Molloy AG, Waddington JL (1984): Dopaminergic behavior stereospecifically promoted by the $D_{1}$ agonist R-SKF 38393 and selectively blocked by the $\mathrm{D}_{1}$ antagonist $\mathrm{SCH}$ 23390. Psychopharmacology 82(4):409-410

Parashos SA, Marin C, Barone P, Kapitzoglou-Logothetis V, Chase TN (1990): Effect of chronic $D_{1}$ and/or $D_{2}$ dopa- mine antagonist treatment on SKF 38393-induced non-stereotyped grooming. Psychopharmacology 102(3):411-413

Pavlov IP (1927): Conditioned Reflexes. London, Oxford University Press

Pickens RW, Crowder WF (1967): Effects of CS-US interval on conditioning of drug response, with assessment of speed of conditioning. Psychopharmacologia 11(1):88-94

Rocha JB, Santos JE, Rocha LK., Kleinpaul ER (1997): Undernutrition during suckling changes the sensitivity to haloperidol and chlorpromazine in two behavioural measures in weaning rats. Pharmacol Toxicol 81(3):114123

Sanberg PR (1980): Haloperidol-induced catalepsy is mediated by postsynaptic dopamine receptors. Nature 284(5755):472-473

Sanberg PR, Bunsey MD, Giordano M, Norman AB (1988): The catalepsy test: its ups and downs. Behav Neurosci 102:748-759.

Schiff SR, Bridger WH, Sharless NS, King JJ (1980): Conditioning using drugs affecting dopaminergic systems as unconditioned stimuli: Behavioral and biochemical evidence. Psychopharmacol Bull 16:24-27

Schiff SR (1982): Conditioned dopaminergic activity. Biol Psychiatry 17(2):135-155

Seeman P (1980): Brain dopamine receptors. Pharmacol Rev 32:229-313

St. Jean A, Donald MW, Ban TA (1964a): Uses and abuses of antiparkinsonian medication. Am J Psychiatry 120:801803

St. Jean A, Donald M, Ban TA (1964b): Interchangeability of Antiparkinsonian medication. Am J Psychiatry 120: 1189-1190

Stanley ME, Glick SD (1976): Interaction of drug effects with testing procedures in the measurement of catalepsy. Neuropharmacology 15(7):393-394

Suchman AL, Ader R (1992): Classic conditioning and placebo effects in crossover studies. Clin Pharmacol Ther 52(4):372-377

Tilson H A, Rech RH (1973): Conditioned drug effects and absence of tolerance to d-amphetamine induced motor activity. Pharmacol Biochem Behav 1:149-153

Undie AS, Friedman E (1988): Differences in the cataleptogenic actions of SCH 23390 and selected classical neuroleptics. Psychopharmacology 96:311-316

Ushijima I, Mizuki Y, Yamada M (1995): Development of tolerance and reverse tolerance to haloperidol- and $\mathrm{SCH}$ 23390-induced cataleptic effects during withdrawal periods after long-term treatment. Pharmacol Bioch Behav 50(2):259-264

Vital MABF, Frussa-Filho R, Palermo-Neto J (1995): Effects of monosialoganglioside on dopaminergic supersensitivity. Life Sci 56(26):2299-2307

Wise RA, Bozarth MA (1987): A psychomotor stimulant theory of addiction. Psychol Reviews 94:469-492

Wise RA, Rompre P-P (1989): Brain dopamine and reward. Annu Rev Psychol 40:191-225 